Trauma Surgery \& Acute Care Open

\title{
Atypical profile of aortic injury associated with blunt trauma in the metropolitan area of Japan
}

\author{
Shusuke Mori, ${ }^{1}$ Tomohiko Ai, ${ }^{1,2}$ Yasuhiro Otomo ${ }^{1}$
}

\begin{abstract}
- Additional material is published online only. To view please visit the journal online (http://dx.doi.org/10.1136/ tsaco-2019-000342).

'Trauma and Acute Critical Care Center, Tokyo Medical and Dental University, Tokyo, Japan ${ }^{2}$ Indiana University School of Medicine, Indianapolis, Indiana, USA
\end{abstract}

Correspondence to Dr Shusuke Mori, Tokyo Medical and Dental University, Tokyo 113-8510, Japan; shunasu@ yahoo.co.jp

This study was presented at 4 th World Trauma Congress 2018 at San Diego, CA, September 26-29, 2018 (c) Author(s) (or their employer(s)) 2019. Re-use permitted under CC BY-NC. No commercial re-use. See rights and permissions. Published by BMJ.

To cite: Mori S, Ai T, Otomo Y. Trauma Surg Acute Care Open 2019:4:e00342.

\section{ABSTRACT}

Background Aortic injury caused by blunt trauma is a critical medical condition that requires extraordinary caution in the treatment. It is often caused by direct hit and high-speed deceleration in motor vehicle accidents. We reviewed and analysed the cases of aortic injury that referred to our institution located in the midst of the metropolitan area of Tokyo, Japan.

Methods We retrospectively reviewed the blunt trauma cases transferred to Tokyo Medical and Dental University Hospital in the past 10 years. All cases with aortic injury were analyzed regardless of the AIS scores. Results: Between 2007 and 2017, a total of 3500 blunt trauma cases were transferred. Nineteen cases showed aortic injuries associated with blunt trauma (Age: $63.5 \pm 15.6$ y.o.; 15 males). Thirteen patients were injured by fall, four patients were senior pedestrians hit by cars, one was injured while riding a motor bike, and one was hit by a train. A total of 11 cases presented a cardiopulmonary arrest on arrival; 8 severe aortic injuries, 1 cardiac rupture; and 2 multiple injuries. Eight cases were alive on arrival; 3 Stanford type A aortic dissections, 3 Stanford type B aortic dissections, and 2 aortic ruptures. Two cases of Stanford type A dissection underwent emergency repairs, whereas all 3 type $B$ dissections went on a good course with conservative treatment.

Conclusions Aortic injury caused by blunt trauma seems to be rare in a metropolitan area in Japan. In addition, the leading cause in our cases was fall, which might be a rare cause of aortic injuries in the other countries. Our observation might be a manifestation of population aging.

\section{INTRODUCTION}

Aortic injury is a rare, but very critical, medical condition that requires urgent care with extraordinary caution. It has been classified in four types by the Society for Vascular Surgery depending on the type of condition: type 1 , intimal tear; type 2 , intramural hematoma; type 3, pseudoaneurysm; and type 4 , rupture. ${ }^{1}$ Recently, a new classification has been proposed along with the development of new therapeutic methods such as endovascular repair and aortic balloon occlusion techniques. ${ }^{2}$ However, it has been reported that $80 \%$ of severe cases are fatal and the victims die before arriving at trauma centers. In the USA, the morbidity and mortality associated with traumatic aortic injury are approximately $30 \%$ within the first 24 hours. ${ }^{3}$ Some patients demonstrate progressive or delayed onset of aortic injuries, mostly aortic dissections, which are treatable with timely and proper diagnosis and treatments. ${ }^{45}$
In this study, we retrospectively reviewed and analyzed the cases of aortic injury associated with blunt trauma that were referred to our hospital in the past 10 years, one of the largest trauma and emergency centers, located in the metropolitan area in Japan. Very interestingly, the incidence of blunt aortic injuries seems to be far less than in US and European countries, and the mechanisms of injury was also unique compared with the other countries.

\section{PATIENTS AND METHODS \\ Study setting}

This study was conducted in accordance with the ethical principles stated in the Declaration of Helsinki. In patients with cardiopulmonary arrest, they were deemed to be waived by the ethical committee since all patients were de-identified. Tokyo Medical and Dental University (TMDU) Hospital is located in the eastern metropolitan area of Tokyo, Japan. The population in this area is approximately 1.5 million within a 15 -kilometer radius, and five tertiary emergency centers cover the area. The total number of the tertiary emergency centers in Japan is 246 (the total population is approximately 120 million).

\section{Study design and data}

The patient records were retrospectively reviewed between 2007 and 2017. Approximately 80000 patients were referred to the emergency center of TMDU Hospital by ambulance, and a total of 30000 patients were admitted for acute care and/or observation. Of these, 3500 cases were related to blunt traumas. The severely wounded patients, in-shock patients (systolic blood pressure $<100 \mathrm{~mm} \mathrm{Hg}$ and heart rate $>100 \mathrm{bpm}$ ), and suspicious patients judged by the physicians were screened for aortic injury using a chest X-ray, an ultrasonography, a CT, and a CT with contrast media if necessary. Cardiopulmonary arrest (CPA) cases were treated by standard cardiopulmonary resuscitation (CPR) protocols and massive saline infusion or blood transfusion of blood type $\mathrm{O}$ if massive bleeding was recognized or confirmed by blood hemoglobin levels. The CPR procedures were terminated after $>30$ minutes at the discretion of the emergency room (ER) physicians with agreement of family members. If cardiac tamponade was found, immediate pericardiocentesis either by percutaneous puncture or thoracotomy was performed, then immediate consultation with cardiothoracic surgeons was made. The deceased patients were examined by a postmortem CT or an ultrasonography to confirm the cause of death. 


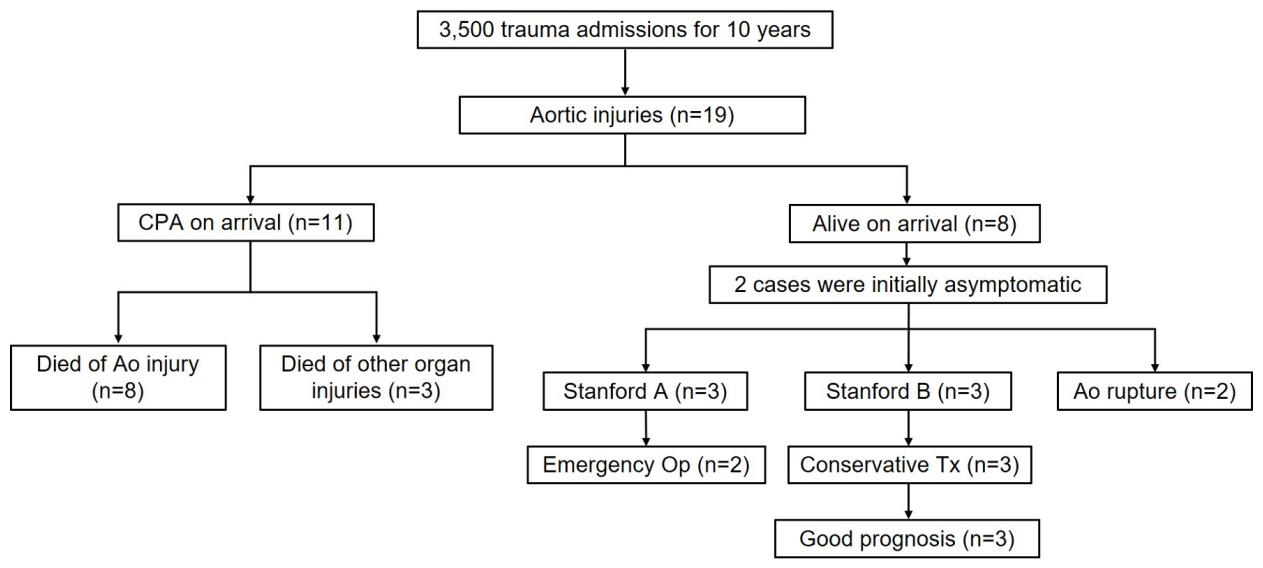

Figure 1 Assortment of cases with aortic injuries caused by blunt trauma in this study. Ao, aortic; CPA, cardiopulmonary arrest; Op, operation; Tx, therapy.

\section{RESULTS}

Of the 3500 blunt trauma cases, 19 patients were diagnosed with aortic injury. Eleven patients presented cardiopulmonary arrest on arrival at the hospital brought by emergency medical services (EMS), and eight patients were alive on arrival. Standard CPR was immediately performed by the EMS at the scene or during transfer to our institution when CPA was identified. Eight patients with blunt trauma regardless of stability of vital signs were transferred carefully with hemostasis if necessary. In the 11 patients showing CPA on arrival, 8 patients died of aortic injuries confirmed by a postmortem CT, and 3 patients were judged to have died of other organ injuries by a CT and/or other modalities coupled with an inspection. Of the eight patients alive on arrival, two patients were initially asymptomatic and underestimated. Three patients were diagnosed with Stanford type A aortic dissection, three patients were Stanford B aortic dissection, and two patients were aortic rupture (figure 1).

Table 1 summarises the deceased patients. The mean age $( \pm S D)$ was $60.5 \pm 16.2$ years and eight patients were male (72.2\%). Six patients showed aortic tear, four showed severe aortic injury, and one showed Stanford type B aortic dissection. Seven patients were injured by fall (63.6\%), three were hit by automobiles $(27.3 \%)$, and one was hit by a train (9.1\%). Despite the CPR with massive drip infusion and/or blood transfusion followed by attempts to stop bleeding (eg, aortic clamp), eight victims died of aortic injury, one died of cardiac rupture, and two died of multiple organ injury. There were not so many rooms for the cardiac surgeons to repair aortic injuries due to cardiac arrest.

Table 2 summarizes the eight patients who were alive on arrival. The mean age $( \pm$ SD) was $67.5 \pm 14.8$ years, and seven patients were male $(87.5 \%)$. Six $(75 \%)$ patients were injured by fall, and two were hit by automobiles. Three patients were diagnosed with Stanford type A aortic dissection (37.5\%), three were diagnosed with Stanford type B aortic dissection (37.5\%), one was diagnosed with contained rupture of the descending aorta $(12.5 \%)$, and one was diagnosed with perforated descending aorta $(12.5 \%)$. One patient was deceased on the same day despite an immediate repair by thoracotomy.

Two patients of type A aortic dissection underwent emergency repair operations, whereas one patient with thrombus formation was treated conservatively. Without any surgical or radiological intervention, this 72-year-old patient was discharged on hospital day 38 (see online supplementary figure 1). Three patients with Stanford type B aortic dissection were treated conservatively, and were discharged or transferred on average $( \pm S D)$ of $36.5 \pm 2.1$ hospital days. Importantly, two patients did not complain of apparent suspicious symptoms after injury. A 74-year-old man had complained of chest pain 3 weeks after he hit his chest by fall from stairs. This patient showed dissection of the descending aorta with impending rupture (see online supplementary figure 2 ), and he was transferred to another hospital for urgent repair since the surgical room was occupied by other patients. A

\begin{tabular}{|c|c|c|c|c|}
\hline Age/sex & Mechanism of injury & Types of Ao injury & AAST-OIS grade ${ }^{20}$ & Cause of death \\
\hline $41 \mathrm{~F}$ & Fall & Stanford B dissection & IV & Multiple organ injuries \\
\hline $35 \mathrm{M}$ & Hit by a $40 \mathrm{mph}$ train & Total transection of Ao & VI & Ao injury \\
\hline $77 \mathrm{~F}$ & Pedestrian hit by a track & Total transection of Ao & $\mathrm{VI}$ & Ao injury \\
\hline $74 \mathrm{M}$ & Fall & Total transection of Ao & $\mathrm{VI}$ & Cardiac rupture \\
\hline $69 \mathrm{M}$ & Motorbike collided by a car & Total transection of Ao & VI & Ao injury \\
\hline $55 \mathrm{M}$ & Fall & Ao rupture & V & Ao injury \\
\hline $67 M$ & Fall & Ao rupture & v & Ao injury \\
\hline $69 \mathrm{M}$ & Pedestrian hit by a car & Ao rupture & V & Ao injury \\
\hline $39 \mathrm{M}$ & Fall & Total transection of Ao & VI & Ao injury \\
\hline $58 \mathrm{~F}$ & Fall & Ao rupture & v & Ao injury \\
\hline $82 M$ & Fall & Total transection of Ao & $\mathrm{VI}$ & Multiple organ injuries \\
\hline
\end{tabular}

AAST-OIS, American Association for the Surgery of Trauma-Organ Injury Scale; Ao, aorta/aortic; mph, miles per hour. 
Table 2 Alive on arrival at the hospital cases showing aortic injury by blunt trauma

\begin{tabular}{|c|c|c|c|c|c|c|}
\hline Age/sex & Mechanism of injury & Types of Ao injury & $\begin{array}{l}\text { AAST-OIS } \\
\text { grade }^{20}\end{array}$ & $\begin{array}{l}\text { Other organ } \\
\text { injuries }\end{array}$ & Treatment & Prognosis \\
\hline $74 M^{* *}$ & $\begin{array}{l}\text { Fall from stairs, hit his chest } 3 \text { weeks } \\
\text { before }\end{array}$ & $\begin{array}{l}\text { Contained rupture of } \\
\text { descending Ao }\end{array}$ & IV & None & Transferred to tertiary TC & Unknown \\
\hline $39 M$ & Fall from 5 feet & Perforated descending Ao & IV & Open fracture of LE & Thoracotomy & Died on the same day \\
\hline $79 M$ & Fall from stairs, 15 steps & Stanford B dissection & IV & Cervical Fx & BP control & D/c on 35th day \\
\hline $62 \mathrm{~F}$ & Pedestrian hit by a taxi & Stanford A dissection & V & $\begin{array}{l}\text { Brain, pelvis, Fx } \\
\text { of LEs }\end{array}$ & $\begin{array}{l}\text { Total arch replacement on } \\
\text { day } 8\end{array}$ & D/c on 116 th day \\
\hline $56 \mathrm{M}$ & $\begin{array}{l}\text { Fall from standing, chest pain after } \\
3 \text { hours }\end{array}$ & Stanford A dissection & V & None & $\begin{array}{l}\text { Ascending Ao replacement } \\
\text { on day } 1\end{array}$ & D/c on 116 th day \\
\hline $72 \mathrm{M}+\dagger$ & Fall from 17 feet & Stanford A dissection & V & Spine Fxs & BP control & D/c on day 38 \\
\hline $86 \mathrm{M}$ & Struck by a car & Stanford B dissection & IV & Brain, lung, pelvis & BP control & D/c on day 38 \\
\hline $72 \mathrm{M}$ & Fall & Stanford B dissection & IV & None & BP control & Transferred \\
\hline
\end{tabular}

* online supplementary figure 2

† online supplementary figure 1

AAST-OIS, American Association for the Surgery of Trauma-Organ Injury Scale; Ao, aorta/aortic; BP, blood pressure; D/c, discharge; Fx, fracture; LE, lower extremity; TC, trauma center.

56-year-old man had complained of chest pain 3 hours after fall. He showed retrograde aortic dissection in the ascending aorta (Stanford type A) and underwent semi-urgent surgery after the diagnosis was confirmed.

\section{DISCUSSION}

Blunt aortic injury is the second leading cause of trauma related to death in the Western countries, being head injury the first. ${ }^{6}$ Severe cardiovascular damages such as rupture, tear, and dissection of aorta (grade 4) can cause a fatal outcome. ${ }^{7}$ In most of the patients, blunt injury on the chest physically damages the heart and the aorta, which may often lead to almost immediate death. Rapid deceleration by collisions can tear the descending aorta that tightly attaches to the body beside the vertebrae. ${ }^{8}$ Survivors are usually limited to the cases with grades 1-3 (ie, mild to moderate) injury. In this study, all the victims with > grade 3 injury (11 patients listed in table 1 ) were found to be in cardiopulmonary arrest probably immediately after the injury. It seems that these victims could not be rescued by any means.

Therefore, the number of surgical cases is very limited. Kodali et al treated 105 patients with thoracic aortic injury between 1969 and 1989 in Vancouver, Canada. They reported that site of injury was mostly aortic isthmus, just distal of the origin of left subclavian artery (91\% of 105 patients). Only 50 (43\%) patients could undergo surgical management, and 36 survived. All non-surgical group died before or after arrival. ${ }^{9}$ Schmidt and Jacobson treated 41 patients with thoracic aortic injury between 1974 and 1983 in Loma Linda, California. They reported that 41 patients arrived alive, and 37 patients could take repair operations. Most injuries were distal to the left subclavian artery (97. 6\%), and they claimed that most of the aortic injury can be repaired safely. ${ }^{10}$ Gammie et al treated 52 patients with traumatic thoracic aortic ruptures between 1988 and 1997 in Pittsburgh, Pennsylvania. Twenty-six patients (50\%) could take repair operations, and 22 were rescued. ${ }^{11}$ Hunt et al treated 144 patients of substantial thoracic aortic injury out of 63507 hospitalized trauma patients between 1988 and 1994 (North Carolina Trauma Registry). Out of 144 patients, 120 (83.9\%) cases were caused by motor vehicle collision and only three patients were injured by fall (2.1\%). Twenty-six patients (18.1\%) died in the ER, 98 patients $(83.1 \%)$ could take operations, and 80 patients
(81.6\%) could be discharged. ${ }^{12}$ These reports indicate that the survival rate is relatively high if patients are stable until surgical treatments.

Most of the injuries in these reports were caused by high-speed deceleration in motor vehicle collisions. Compared with these cases, 13 (68.4\%) of our patients were injured by fall, and 11 died of aortic rupture or tear and the seven survivors presented aortic dissection. This difference may be associated with the difference of social environment. In the USA, approximately 37461 people were killed by traffic accidents, yielding 109.4 fatalities per 100000 population in 2015. The number of deaths by traffic collision in Japan was 4698 per year, yielding 37 fatalities per 100000 population in $2016 .{ }^{13}$ Even, this number drops to almost one twentieth in the metropolitan areas. In addition, senior population (65 years and over) in the USA was $14.9 \%$ of the total population in 2015 whereas senior population in Japan was $27.7 \%$ of the total population in $2017 . .^{14}$ In our study, 7 out of 13 fall cases were senior, and four victims involved in the traffic collisions were senior pedestrians hit by automobiles.

What we have learned from this study is the importance of timely diagnosis and treatment to save the survivors of traumatic aortic injury. Traumatic aortic dissection has three types of onset: immediate, progressive, and delayed. ${ }^{16}$ Diagnosis of progressive aortic dissection after blunt chest trauma is sometimes difficult because it develops and becomes obvious slowly as summarized in the Guidelines for the Diagnosis and Management of Blunt Aortic Injury. ${ }^{17}$ The onset varies in accordance with strength of the impact and mechanism of the injury. ${ }^{18}$ Even a seemingly minor crash occasionally turns out to be a serious aortic injury. ${ }^{16} 19$

\section{CONCLUSION}

In the past 10 years, we have experienced 19 cases of aortic injury transferred to the ER. The average age was 63.5 years. Eleven patients died almost immediately at the scene, and eight patients were alive on arrival (42.1\%). Interestingly, the main cause of injury was fall (68.4\%), whereas motor vehicle collisions are the leading cause in the other countries. Importantly, two patients $(25 \%)$ did not show any chest symptoms initially. These facts gave us an important lesson that blunt traumas need 
extraordinary caution for diagnosis and treatment of elderly populations.

Contributors SM: study conception, design, interpretation, and drafting of article. TA: interpretation and drafting of article. YO: study conception and supervision of the article.

Funding The authors have not declared a specific grant for this research from any funding agency in the public, commercial or not-for-profit sectors.

Competing interests None declared.

Patient consent for publication Obtained.

Ethics approval This study was performed in accordance with the guidelines of researches of human subjects in Tokyo Medical and Dental University.

Provenance and peer review Not commissioned; externally peer reviewed.

Open access This is an open access article distributed in accordance with the Creative Commons Attribution Non Commercial (CC BY-NC 4.0) license, which permits others to distribute, remix, adapt, build upon this work non-commercially, and license their derivative works on different terms, provided the original work is properly cited, appropriate credit is given, any changes made indicated, and the use is non-commercial. See: http://creativecommons.org/licenses/by-nc/4.0/.

\section{REFERENCES}

1. Heneghan RE, Aarabi S, Quiroga E, Gunn ML, Singh N, Starnes BW. Call for a new classification system and treatment strategy in blunt aortic injury. J Vasc Surg 2016:64:171-6.

2. Starnes BW, Lundgren RS, Gunn M, Quade S, Hatsukami TS, Tran NT, Mokadam N, Aldea G. A new classification scheme for treating blunt aortic injury. J Vasc Surg 2012:55:47-54

3. Igiebor OS, Waseem M. Aortic trauma. Treasure Island (FL): StatPearls, 2018.

4. Patel NR, Dick E, Batrick N, Jenkins M, Kashef E. Pearls and pitfalls in imaging of blunt traumatic thoracic aortic injury: a pictorial review. Br J Radiol 2018;91:20180130.

5. Agostinelli A, Carino D, Borrello B, Marcato C, Volpi A, Gherli T, Nicolini F. Blunt traumatic injury to the thoracic aorta treated with thoracic endovascular aortic repair: a single-centre 20-year experience. Interact Cardiovasc Thorac Surg 2019:28:17-22.

6. O'Connor JV, Byrne C, Scalea TM, Griffith BP, Neschis DG. Vascular injuries after blunt chest trauma: diagnosis and management. Scand I Trauma Resusc Emerg Med 2009;17:42.
7. Sznol JA, Koru-Sengul T, Graygo J, Murakhovsky D, Bahouth G, Schulman Cl. Etiology of fatal thoracic aortic injuries: secondary data analysis. Traffic Inj Prev 2016;17:209-16

8. Ramanath VS, Oh JK, Sundt TM, Eagle KA. Acute aortic syndromes and thoracic aortic aneurysm. Mayo Clin Proc 2009;84:465-81.

9. Kodali S, Jamieson WR, Leia-Stephens M, Miyagishima RT, Janusz MT, Tyers GF. Traumatic rupture of the thoracic aorta. A 20-year review: 1969-1989. Circulation 1991:84(5 Suppl):|l|40-6.

10. Schmidt CA, Jacobson JG. Thoracic aortic injury. A ten-year experience. Arch Surg 1984:119:1244-6.

11. Gammie JS, Shah AS, Hattler BG, Kormos RL, Peitzman AB, Griffith BP, Pham SM. Traumatic aortic rupture: diagnosis and management. Ann Thorac Surg 1998:66:1295-300.

12. Hunt JP, Baker CC, Lentz CW, Rutledge RR, Oller DW, Flowe KM, Nayduch DA, Smith C, Clancy TV, Thomason MH, et al. Thoracic aorta injuries: management and outcome of 144 patients. J Trauma 1996:40:547-55.

13. OECD. Road accidents (indicator). 2019

14. United States Census Bureau. Profile America Facts for Features: Older Americans Month: May 2017. 2017. https://www.census.gov/newsroom/facts-for-features/2017/ cb17-ff08.html.

15. Statistics Bureau of Japan. Statistical Handbook of Japan 2018 Chapter 2 Population. Japan: Statistics Bureau. 2018. http://www.stat.go.jp/english/data/handbook/c0117. $\mathrm{html}$.

16. Penn JL, Martindale JL, Milne LW, Marill KA. Aortic dissection associated with blunt chest trauma diagnosed by elevated D-dimer. Int I Surg Case Rep 2015;10:76-9.

17. Nagy K, Fabian T, Rodman G, Fulda G, Rodriguez A, Mirvis S. Guidelines for the diagnosis and management of blunt aortic injury: an EAST Practice Management Guidelines Work Group. J Trauma 2000:48:1128-43.

18. Daghfous A, Daiki M, Ben Khélifa El Moncer R, Maarouf M, Felah S, Zoghlami A, Rezgui-Marhoul L. [Acute traumatic thoracic aortic rupture in double localisation]. Ann Cardiol Angeiol 2014;63:51-4.

19. Bade-Boon J, Mathew JK, Fitzgerald MC, Mitra B. Do patients with blunt thoracic aortic injury present to hospital with unstable vital signs? A systematic review and meta-analysis. Emerg Med J 2018:35:231-7

20. Moore EE, Malangoni MA, Cogbill TH, Shackford SR, Champion HR, Jurkovich GJ, McAninch JW, Trafton PG. Organ injury scaling. IV: Thoracic vascular, lung, cardiac, and diaphragm. J Trauma 1994:36:299-300. 